\title{
DE HOLLANDSCHE IJZEREN SPOORWEG-MAATSCHAPPIJ IN HET JAAR 1876.
}

De Hollandsche IJzeren Spoorweg-Maatschappij heeft in 1876 geëxploiteerd haar eigen spoorwegen (Rotterdam-Haarlem-Amsterdam en Haarlem-Uitgeest, te zamen lang 102 kilometers;

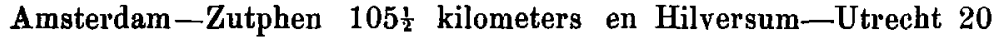
kilometers) en het gedeelte van den Staatsspoorweg van Nieuwe Diep over Uitgeest naar Zaandam (lang 72 kilometers). Het gedeelte Amersfoort-Zutphen, lang 60 kilometers, werd den 15den Mei 1876 voor de publieke dienst geopend.

De opbrengst van het reizigersvervoer op de oude lijnen Amsterdam-Rotterdam en Haarlem-Uitgeest was $f 75.600$ hooger dan in het vorige jaar. Op de Noord-Hollandsche Staatsspoorweg bedroeg die toeneming $f$ 12.500. De Oosterspoorweg, die in 1875 per kilometer $f 7000$ an reizigersvervoer opbragt, gaf nu slechts $f 6230$, ten gevolge van het sedert 15 Mei 1876 exploiteeren van het nog weinig personenverkeer hebbende gedeelte AmersfoortZutphen.

De bestelgoederen-opbrengst klom op de lijnen Amsterdam-Rotterdam en Haarlen-Uitgeest met $f 5000$, en bleef op den NoordHollandschen Staatsspoorweg onveranderd.

De Oosterspoorweg leverde $f 54.200$, dus $f 14.200$ meer, dan in het vorige jaar, aan bestelgoed op.

Het vracht- en ijlgoederenverkeer ging op de oude lijnen met $f 14.500$ terug, maar bragt op den Oosterspoorweg. f 175.000 of $f 1705$ per kilometer op (dus $f 65$ meer dan in 1875). Het reevervoer bleef op de oude lijnen ongeveer gelijk aan het vorige jaar. Op den Oosterspoorweg klom het van $f 5.600$ op $f 10.000$.

Het bedrag aan diverse ontvangsten der exploitatie was op de oude lijnen bewesten Amsterdam $f \mathbf{1 5 . 6 0 0}$ hooger, dan in 1875 .

De rentegevende eigendommen en woningen droegen daartoe $f 2.000$ bij; de pacht der buffetten steeg met $f 6.400$ en het saldo Econ. 1877. 
der wagenhuur-afrekening (waaronder ook de Oosterspoorweg begrepen is) wees eene hoogere bate van $f 13.500$ aan.

Tegenover deze vermeerderingen, waarbij nog gevoegd moet worden eene verhooging der zandlevering aan particulieren ad $f 21.000$, staat eene vermindering door niet verkoop van afval van de werkplaats ten bedrage van $f 6.500$.

Op den Oosterspoorweg is ook eene vermeerdering van $\mathrm{f} 5.200$ te constateeren, voornamelijk ten gevolge van de huur der woningen en de pacht der restauratie te Apeldoorn.

De zandaanvoer bragt ruim $f 123.000$ op , na aftrek der onkosten.

De opbrengst der zandtreinen voor werken in aanleg en voor onderhoud was op de oude lijnen $f 10.000$ meer en op den Oosterspoorweg $f 5.300$ minder, dan in 1875 .

De telegraaf bragt in 1876 langs alle lijnen te zamen $f 2.300$ minder op dan in 1875 , veroorzaakt door het opheffen der groote stations als bestemming der telegrammen, waardoor alle voor die plaatsen aangeboden telegrammen over de Rijkstelegraaf hunne bestemming bereikten, en dus een deel der opbrengsten aan het Rijk toekwam.

In het Verslag is de exploitatierekening van den ouden Hollandschen Spoorweg en den Oosterspoorweg te zamen gevoegd, terwijl het gedeelte Amersfoort-Zutphen eerst met 15 Mei 1876 is geopend. Wij deelen daarom alleen de eijfers over 1876 mede van deze spoorwegen.

Reizigers . . . . . . . . . . . . $f 2.507 .298,11^{\circ}$

Bagage der reizigers . . . . . . . . . $36.706,63^{\circ}$

Bestelgoederen . . . . . . . . . . . ${ }^{n} 343337,81^{5}$

Vrachtgoederen . . . . . . . . . . . . ${ }^{n} 326.621,86$

IJgoederen . . . . . . . . . . . . .

Zand . . . . . . . . . . . . . . . " 145.320,34

Diverse voor verkoop van drukwerken, bewaar-

gelden, bestelloonen, enz. . . . . . . . . n $19.617,24$

Paarden, vee en rijtuigen . . . . . . . .

Telegraaf . . . . . . . . . . . . . ${ }_{\pi} 9^{9} 292,86^{5}$

Diversen, als opbrengst van eigendommen, huur

van woningen, buffetten, post-compartimenten,

wagens, enz. . . . . . . . . . . . $\$ 88.188,41^{\mathrm{s}}$

Zandtreinen ten behoeve van eigen werken $\cdot \frac{\pi}{f} \frac{29.561,00}{3.654 .086,77^{6}}$

Het totaal der opbrengsten van de oude lijnen AmsterdamRotterdam-Uitgeest beliep $f 2.594 .995,23$ tegen $f 2.469 .669,02$ in 
1875. De Oosterspoorweg bragt op $/ 1.059 .091,545$ tegen $/ 665.390,73^{5}$ in 1875. De gemiddelde opbrengst per kilometer van de oude lijnen was $f 25.317$ tegen $f 24.094$ in 1875 . Deze opbrengst was over de verschillende baanvakken aldus verdeeld.

Amsterdam-Haarlem . . . . $f 30.404$

Haarlem-Leiden . . . . . . , 18.262

Leiden - den Haag . . . • 25.161

त 25.354

Den Haag-Rotterdam . . . . „33.289

Haarlem-Uitgeest . . . . . „ 11.076

ॠ11.664

Van den Oosterspoorweg bragt het gedeelte Amsterdam-Amersfoort op per kilometer $f 13.872$ tegen $f 11.226$ in 1875 , en het gedeelte Hilversum-Utrecht $f 8.304$ tegen $f 7.046$ in 1875 . Het gedeelte Amersfoort-Zutphen (15 Mei 1876 geopend) bragt op $f 2.233$.

De uitgaven voor de Hollandsche en Oosterspoorweg te zamen bedroegen in 1876:

Onderhoud van den weg . . . . . . . $f$ 359.277,94

Buitengewone werken . . . . . . . . . . n $2.579,96$

Onderhoud der stations en werkplaats . . . . $n \quad 80.955,50$

Directie en toezigt der baan . . . . . . . n 31.949,20

Onderhoud der locomotieven, rijtuigen, enz. . . ${ }^{n} 232.022,55^{5}$

Directie der werkplaats en der tractie . . . . " $15.040,55^{5}$

Daggelden van machinisten, stokers, brandstoffen, smeer, water voor locomotieven, enz. . . . \ 374.022,24

Tractementen voor de inspecteurs, stationchefs, opzigters, conducteurs, wachters, enz. . . . $\gg 389.119,25^{5}$

Kosten der goederen-, hulp- en bestelkantoren. . " 192.494,49

Traktementen van de ambtenaren der controle

en handelszaken . . . . . . . . . . . $, 57.646,06$

Raad van administratie . . . . . . . . . $n 17.400,00$

Traktement van den administrateur en andere

beambten, benevens kosten van de bureaux, be-

lasting, enz. . . . . . . . . . . . 134.422,48

f $1.873,065,75^{5}$

De exploitatiekosten hebben $51^{28} \mathrm{pCt}$. van de ontrangsten bedragen, tegen $50^{5 B}$ pCt. in 1875.

In het vorige verslag deelden wij mede, dat de Reservekas meer bevatte dan één millioen, zijnde het maximum volgens de statuten bepaald. Gedurende 1876 is betaald ter vereffening van het ongeluk van Augustus $1874 f 28.399,78$, terwijl de gemaakte rente bedroeg 
$f 54.904,94$. Door de waarde-vermindering der effecten, daalde de bezitting der Reservekas beneden het millioen, zoodat een aanvulling van $f 5.222,20^{\mathrm{s}}$ uit de winst van 1876 moet worden bijgestort.

De exploitatie van den Noord-Hollandschen Staatsspoorweg gaf de volgende resultaten.

De opbrengst bedroeg:

1875

Reizigers . . . . . . f 264.862,40

Bagage der reizigers . . $n 3.675,77$

Bestelgoederen . . . . $n 24.459,83^{5}$

Vrachtgoederen . . . . $n 52905,38$

IJlgoederen . . . . : . $\gg 14.709,02 \mathrm{~s}$

Paarden, vee en rijtuigen . $n 14742,25$

Laad-, los- en bestelloon . \# 21.422,09

Toevallige baten . . . . n 5.525,61

Telegraaf . . . . . . $n 44663,99$

Diverse baten en zandvervoer $, \quad 5.612,42^{5}$

f. $412.578,77^{5}$
1876

$f 277.388,98$

$3.771,25^{5}$

$23.880,41^{5}$

$40.840,59^{5}$

$17.456,64^{5}$

ᄁ 13923,55

त $18.675,58_{5}$

ᄁ $7.024,58^{5}$

त $3.524,72^{5}$

n $5.126,13$

De gezamenlijke ontvangsten van de Noord-Hollandsche Staatsspoorwegen in 1875 en 1876 verschilden dus zeer weinig. De gemiddelde opbrengst per kilometer bedroeg $f 5.797$. Het meeste bragt op het gedeelte Uitgeest-Alkmaar, $f 7.755$, en het minste Uitgeest-Zaandam $f 3.058$.

De uitgaven beliepen:

1875

Weg en werken . . . $f$ 72.043,68

Tractie . . . . . . "112.005,21

Beweging . . . . . . . $\gg 80.615,66^{5}$

Onkosten-rekening . . . . ${ }^{n} 16.926,29^{5}$

Vernieuwingsfonds. . $\cdot \frac{n}{f 304.989} \frac{23,17}{77^{5}}$
1876

$f \quad 69.247,06^{5}$

n $104.803,00$

n $82.790,41^{5}$

त $18.485,85$

$\begin{array}{r}n \quad 23.398,32 \\ \hline f 298.724,65\end{array}$

De exploitatie-kosten bedroegen $72^{57}$ pCt. tegen $73^{92} \mathrm{pCt}$. in 1875. Van de zuivere opbrengst moet worden uitbetaald aan den Staat $f 109.743,83$, dus $f 1.725,45$ meer dan in 1875 , hoewel de ontvangsten minder bedroegen. Daar de exploitatie-kosten minder waren dan in het vorig jaar, hield de Maatschappij over $f 3.143 .98^{5}$, terwijl in 1875 er een tekort was van $f 427,09^{5}$.

In het Verslag noemt de Directie het feit, dat, niettegenstaande de mindere inkomsten, de Staat meer ontvangt, en de Maatschappij wint, in plaats van verliest, eene nieuwe bijdrage ter beoordeeling ran de vreemde werking der voorwaarden van exploitatie. Dit is 
slechts ten deele juist; hadden de exploitatio-kosten in 1876 niet minder bedragen dan in 1875, dan zou ook de Maatschappij wederom hebben verloren, zooals in 1875 .

Op de algemeene vergadering van aandeelhouders, den 31sten Maart 1877 in het Odeon te Amsterdam gehouden, waren 117 aandeelen vertegenwoordigd, uitbrengende 68 stemmen. De rekening en de balans werden goedgekeurd en het dividend bepaald op $f 58$ per aandeel van $f 1000$, waarvan in October reeds een voorloopig dividend van $f 20$ was betaald. Even als het vorig jaar komt op de balans nog voor de verbindingslijn Leiden-Woerden voor $f 67.577,01$. Tot op 31 December 1876 had aan aanleg gekost het gedeelte Amsterdam-Amersfoort-Utrecht $f 9.034 .000$ en Amersfoort-Zutphen $f$ 3.841.000.

De aftredende commissaris Jhr. W. van Loon werd herkozen, en in plaats van den heer Mr. P. C. Hoijnck van Papendrecht, die verzocht had niet meer in aanmerking te komen, gekozen $\mathrm{Mr}$. A. Hoijnck van Papendrecht.

De vergadering magtigde de Directie, om de exploitatie van den ontworpen staatsspoorweg Zaandam-Enkhuizen te aanvaarden en om een overeenkomst te sluiten met de Bergisch-Märkische spoorwegmaatschappij, waarbij deze Maatschappij op zich neemt de exploitatie van het gedeelte der Nederlandsch-Westphaalsche spoorwegmaatschappij van Winterswijk naar Bismarck en Bocholt. Tevens werd de Directie gemagtigd, om de nog niet geplaatste obligation uit te geven.

Op de oude lijnen, waartoe wij ditmaal ook rekenen te behooren de Noord-Hollandsche Staatsspoorweg, werden vervoerd 4.119.929 reizigers; elke reiziger legde gemiddeld af 23 kilometer, en bragt op 52 cent. Van de reizigers maakte gebruikt van de eerste 10 , van de tweede 19 en van de derde klasse $71 \mathrm{pCt}$.

Op den Oosterspoorweg werden vervoerd 991.015 reizigers; elke reiziger legde gemiddeld af 27 kilometer en bragt op 64 cent.

In den loop van het jaar werden vijf personen door den trein gedood.

Op blz. 606 van den vorigen jaargang van het Tijdschrift hebben wij kortelijk medegedeeld de voorwaarden, door de Maatschappij met de Regering gesloten omtrent de exploitatie van Staatsspoorwegen en de verlenging der concessie van den Hollandschen IJzeren spoorweg tot 1 Mei 1917.

Het wetsontwerp, houdende wettelijke bekrachtiging dezer overeenkomst, is den $24^{\mathrm{a}}$ October 1876 verworpen door de Tweede Kamer der Staten-Generaal met 37 tegen 36 stemmen. 
L/s idées marchent, en meer on meer wint de overtuiging veld, dat een spoorweg-onderneming, zelfs die eener particuliere compagnie, geenszins moet beschouwd worden als een gewone industriëele zaak, (fabriek, reederij enz.) maar als een aanvaarde tak van publieke dienst, welke de Staat hier niet, even als de posterijen en telegraafdienst, in eigen beheer heeft, doch bij publiekregtelijke overeenkomst aan bijzandere personen opdraagt. Een spoorweg bezit feitelijk een monopolie, en coneurrentie is meestal onmogelijk. De kosten van aanleg en exploitatie van de meeste nieuwe spoorwegen, slechts enkele uitgezonderd, zijn zoo hoog, dat de opbrengsten naauwelijks de kosten zullen kunnen dekken. Alleen doordien in ons land de tarieven, in vergelijking met België, zeer hoog zijn, brengen de Staatsspoorwegen ten minste redelijk op. $\left({ }^{*}\right)$ - Maar overigens zijn in Nederlard de voordeelige lijnen sedert jaren door partieulieren aangelegd; op voldoende intrest der gelden kan, bij aanleg van nieuwe lijnen, thans zelden vooruitzicht zijn. En toch, het platte land is bijna onbewoonbaar, als er geen spoonwegen zijn. Wil men spoorwegen, dan schiet en niets anders ovep, dan aanleg der spoorwegen door den Staat. Indien de Staat en niet toe durft overgaan om de spoorwegen zelf te exploiteenen, dan kan de Staat, (zooals eenigzins hier te lande de Maatschappij tot exploitatio van Staatsspoorwegen) een Maatschappij met de exploitatio belasten, die dan evenwel geheel als agent der Regering zou kunnen handelen, en in zake van tarieven, het aantal treinen, enz. geheel de bevelen der Regering opvolgen, natuurlijk tegen waarborging eener goede belooning. Het is een geheel ander oogpunt en doel, waarmede een spoorweg geëxploiteerd wordt, of men een spoorweg beschouwt, als een zaak van publieke diønst, waarvoor de Staat behoort te waken; dan wel of een spoorweg is het eigendom en in exploitatio bij een bijzondere matschappij. De pligt van het bestuur eeper maatschappij is to wakpm; dat de aandeelhouders zooveel winst mogelijk ontvangen. 'In thein land als het onzer behoort men te trachten, om de. versohillende spoorwegen zooveel mogelijk in één hand te brengen, omdat: bij de aansluiting van spoorwegen van verschillenda maatschappijon veelal vertraging ontstaat, en centralisatic van deze zaak voordeelig voor het publiek is (zie blz. 120 van dit Tijdschrift).

Is men overtuigd van de waarheid den bovenstaande. beschou-

$\left({ }^{*}\right) \cdot W_{i j}$ zegłen "de Stastąpoorwegen" ol. zonder de exploitatie den vrijwillig daarbij toegevoegde nadeelige lijn Luik-Limburg. 
wingen, dan zal men toestemmen, dat, nu eenmaal besloten is bier te lande op. Staatskosten spoorwegen an te leggen, de Regering geen gelegenheid behoort te laten voorbij gaan, om door naasting eigenaar van spoorwegen te worden, die thans aan partieuliere maatschappijen behooren. In 1880 eindigt de concessie voor de spoorweg Amsterdam-Rotterdam, en kan de Regering dien spoorweg naasten tegen uitkeeving der hoofdsom, die de tot stand brenging zal hebben gekost, en van zoodanige andere sommen, als met voorkennis en goedvinden der Regering tot uitbreiding mogten zija besteed. Op de balans van 1876 wordt door de Directie dezen spoorweg gebragt voor $f$ ' $14,883,000$. De bruto opbrengst van Amsterdam-Rottendam|' bedmoeg $f: 2,271,000$, zoodat na aftrok der exploitatiekosten ongeveer elf ton is overgeschoten.

Wij: begrijpen niet; waarom de Regering van haar regt afstand zou doen, om in 1880 den spoorweg Amsterdam-Rotterdam to naasten.

In Engeland, het land van particuliere nijverheid bij uitnewendheid, gaan krachtige stemmen op, om de spoorwegen van staatswege aan the koopen, even als zulks met de telegrafen ten koste van vele millioenen sterling, met goed gevolg is geschiefl.

Men kent den strijd, dle in Duitschland wordt gevoerd, om al de spoorwegen in eigendom bij de: Rijksregering te doen overgaan.

In Frankrijks worden de spoorwegen hoofdzakèlijk door zes groote spoor'wegmaatschappijen geëxploiteerd; zijlijnen zijn net ondersteuning der Regering aangelegd, en worden door die Maatschappijen geëxploiteerd. De exploitatie der spoerwegen markt ook aldaar een ernstig punt van debat uit. De Ministen van openbare werken beeft zich, vergezeld van twee afgevardigken, van den directeur der spoorwegzakew aan het departement van openbare werken en van eenige ingenieurs, onlangs naar Nederlaurb begeven; om het spoorwegwezen alhier te bestudeeren, en een Verslag opgemaakt, voonkomende op blz. 138: en volgende van dit Tijdschrift. Door de Fansehe Regering is een wetsontwenp ingediend tot goedkeuring van overeenkemster, waarloij kleine en geringe. winsten af werpendè of zelfs venlies gevente spoorwegmatsehappijen op zokere voonwaanden. in eene der zea groote spoorwegmaatschappijen zouden worden opgelost, en dust middelijk goedgekeurl - werd het doow den Minister van opeubarb, werken Christophle roorgestaan stelsel van oplossing van alle kleine matschappijen in de bestaande groote. Na eene beraadslağing vạn zeveu dagen, waarin alle sprekers, zoowel do leden der Commissie van rapporteurs, als de anderen, het wets- 
ontwerp en de denkbeelden des Ministers bestreden hadden, nam de Kamer van Afgevaardigden den 22 Maart 1877 met 231 tegen 192 stemmen het volgende besluit:

${ }_{n}$ Het wetsontwerp wordt op nieuw gesteld in handen der commissie van rapporteurs, ten einde op nieuw te worden onderzocht en omgewerkt naar de volgende beginselen:

"10. Aankoop door den Staat van de lijnen, van welker exploitatie de oorspronkelijke concessionarissen zich mogten willen ontdoen, op de grondslagen der wet van 23 Maart 1874, namelijk tot de reële waarde, met verrekening van de oorspronkelijk voor den aanleg verleende subsidien;

${ }_{n} 20$. Vereeniging van alle in hetzelfde deel des lands gelegen hoofdlijnen onder een zelfde bestuur, ten einde te voorkomen 'dat er, ten koste van den Staat, eene voor de schatkist, voor de exploiterende maatschappijen en weldra ook voor de bevolking uiterst kostbare mededinging tusschen de van staatswege gesubsidieerde lijnen onderling gevoerd worde;

n30. Vaststelling van wezenlijke waarborgen en van reglementaire bepalingen tot verzekering van het regt van den Staat ten opzigte der regeling van de prijzen en van het vervoer, en welke den belanghebbenden de gelegenheid geeft om hunne klagten bij de administratie in te brengen;

"40. Volstrekte en onbeperkte handhaving van het regt van den Staat om, te allen tijde, mits de finantiele bepalingen der bestaande overeenkomsten in haar geheel latende, den aanleg te bevelen van noodig gekeurde nieuwe lijnen, om in het spoorwegnet van het betrokken gedeelte des lands te worden opgenomen;

${ }_{n} 5$ o. In geval de Orleans-spoorwegmaatschappij [want de oplossing van kleine maatschappijen in deze groote maakte het onderwerp der overeenkomsten uit] op de hierboven vastgestelde grondslagen niet mogt willen onderhandelen, zal een zevende groot spoorwegnet, van het Westen en Zuidwesten, worden gevormd om door den Staat te worden geëxploiteord." $\left({ }^{*}\right)$

In Nederland wil men altijd wijzer en voorzigtiger zijn, dan in andere landen; eerst beweerde men, dat Nederland geen spoorwegen noodig had, omdat er goede waterwegen waren; toen, dat de spoorwegen alleen door particulieren en niet door den Staat moesten aangelegd worden, dat zij met zoogenaamd breed spoor

$\left(^{*}\right)$ Dit onderwerp is o. a. besproken in een lezenswaardig artikel van den Moniteur des Iıtérêts Matériels van 25 Maart 1l, waarnaar wij bij dezen verwijzen. 
en niet met smal spoor moesten gebouwd worden. Nadat men door schade en schande wijs is geworden, en de beweging in andere landen heeft moeten volgen, blijft men nu nog hechten aan het verouderde denkbeeld van exploitatie door verschillende groote en kleine particuliere maatschappijen, terwijl men uit het oog verliest, dat feitelijk alles, wat uit een economisch standpunt daarvoor hier te lande vroeger aan te voeren was, thans niet meer bestaat.

's Hage, 15 April 1877.

J. J. van KerirwiJk. 